\title{
Miscible mixtures of polychloroprene and epoxidized polyisoprene
}

\author{
J. B. Nagode* and C. M. Roland $\dagger$ \\ Chemistry Division, Code 6120, Naval Research Laboratory. \\ Washington, DC 20375-5000, USA \\ (Received 20 December 1989; revised 12 February 1990; accepted 13 February 1990)
}

\begin{abstract}
Blends of polychloroprene and epoxidized polyisoprene are demonstrated to be thermodynamically miscible. This miscibility, affirmed by spontaneous interdiffusion between the two polymers, results in the customary single, and composition-dependent, glass transition temperature. Fourier-transform infra-red spectra from the mixture provide direct evidence of specific interaction between the chlorine and the epoxy group. From the invariance of the crystalline melting temperature of the polychloroprene (the equilibrium value of which is determined to be $150^{\circ} \mathrm{C}$ ), a lower limit of $5 \times 10^{-2}$ is estimated for the interaction parameter.
\end{abstract}

(Keywords: polychloroprene; epoxidized polyisoprene; miscible blends; melting point)

\section{INTRODUCTION}

Mixtures of high polymers that exhibit miscibility are of both scientific and technological interest. Much recent work has been directed towards a better understanding of the thermodynamics ${ }^{1-6}$, as well as the dynamic behaviour $^{7-11}$, of miscible blends. In addition to the possibility for novel combinations of properties, the potential improvement in mechanical properties arising from presumed increases in cohesive energy density and chain concentration ${ }^{12-14}$ underlie some of the commercial appeal of miscible polymer blends.

Very few miscible blends happen to be comprised of only rubbery constituents. Aside from mixtures whose components have negligible chemical differences (e.g. isotope mixtures ${ }^{3,15}$ or blends of similar copolymers $^{16-19}$, the only miscible blends of rubbers reported to date consist of polyisoprene with poly(vinyl ethylene $)^{20-23}$, poly(epichlorohydrin) with certain polyacrylates ${ }^{24}$ and chlorinated polyethylene with epoxidized polyisoprene ${ }^{25}$. While the latter blends are miscible due to specific interactions, the miscibility of the polyisoprene and poly(vinyl ethylene) mixture arises from a fortuitous near-equivalence of the polarizabilities and of the expansivities of the components ${ }^{22,26}$. This results in nearly athermal mixing and hence thermodynamic miscibility in the absence of specific interactions. Miscibility in blends of chlorinated polyethylene and epoxidized polyisoprene (a random copolymer of 2-methyl-1,2epoxy-1,4-butanediyl and 2-methyl-1-butenylene) reportedly is due to specific interactions involving the oxirane ring with the chlorine ${ }^{25}$. Miscibility of epoxidized natural rubber with poly(vinyl chloride $)^{27}$ and with both chlorinated polypropylene and a poly(vinylidene chloride) copolymer ${ }^{28}$ has also been reported.

This report describes a study of mixtures of polychloroprene and epoxidized polyisoprene.

* Geo-Centers Inc., Fort Washington, MD 20744, USA

$\dagger$ To whom correspondence should be addressed

\section{EXPERIMENTAL}

The random copolymer of 2,3-epoxy-2-methylbutane and 2-methyl-2-butene was epoxidized natural rubber (ENR) supplied by Guthrie Latex Inc. through the Malaysian Rubber Bureau. The weight-average degree of polymerization, $N$, of the ENR was 3800 and it contained $50 \mathrm{~mol} \%$ oxirane groups. The polychloroprene (CR) was Neoprene WM-1 $(N=4100)$ from E.I. du Pont de Nemours \& Co. Some experiments also utilized a higher-molecular-weight polymer (Neoprene WHV with $N=5000$ ).

Films were obtained by solvent casting from 5\% carbon tetrachloride solutions, followed by vacuum drying for $50 \mathrm{~h}$ at $55^{\circ} \mathrm{C}$. For interdiffusion experiments, thin sheets of the pure components were prepared by compression moulding at $100^{\circ} \mathrm{C}$ for $15 \mathrm{~min}$, followed by room-temperature annealing for $12 \mathrm{~h}$.

A liquid-nitrogen-cooled Perkin-Elmer DSC-2, calibrated with cyclohexane, was used for differential scanning calorimetry, conducted at a heating rate of $20^{\circ} \mathrm{C} \mathrm{min}^{-1}$. The samples were heated to $55^{\circ} \mathrm{C}$ prior to the calorimetry to remove any crystallinity in the $C R$. For crystallization experiments, samples were annealed at temperatures between -13 and $25^{\circ} \mathrm{C}$ for various durations.

An IMASS Co. ADV985 Rheovibron was employed for dynamic mechanical measurements. For qualitative assessment of any interdiffusion, the mechanical spectra were obtained on sheets of the CR and ENR that had been plied together and maintained in contact at $80^{\circ} \mathrm{C}$ in vacuo. Specimens were periodically taken from this laminate for testing.

Fourier-transform infra-red (FTi.r.) spectra were obtained using a Perkin-Elmer model 1800 instrument. The spectra were averaged over 500 scans taken at $2 \mathrm{~cm}^{-1}$ resolution. The samples consisted of thin films cast onto potassium bromide plates, followed by drying under vacuum at $55^{\circ} \mathrm{C}$ for 3 days. An absence of any crystallinity in the CR was ensured by preheating. 


\section{RESULTS}

\section{Miscibility}

The fact that molecularly dispersed components experience equivalent free volumes leads to the expectation that miscible blends will exhibit a single glass transition, intermediate to that of the pure components. Actually, the differing free volume requirements for miscibility may produce distinct glass transitions, even in thermodynamically miscible blends ${ }^{29,30}$. Blends of CR and ENR were found to exhibit only one glass transition in both calorimetric and dynamic mechanical measurements. In the latter data, the single maximum in the loss tangent, associated with the glass transition, was obtained independently of the deformation frequency over a two decade range of frequencies. Such a frequency independence argues against a fortuitous single $T_{\mathrm{g}}$, since obtaining only one transition at all frequencies would require an equivalence in the temperature dependence of the respective components' activation energy for relaxation $^{31}$. The glass transition temperature of the blends exhibited a composition dependence, as displayed in Figure 1 for calorimetry data. This is consistent with morphological homogeneity in the ENR/CR mixtures. Nevertheless, thermodynamic miscibility is not affirmed, since small domain sizes and an extensive interfacial area will suppress the appearance of distinct transitions in calorimetric or dynamic mechanical measurements ${ }^{32,33}$. Alternative experiments are necessary to demonstrate miscibility unambiguously.

The occurrence of spontaneous mixing of initially separated polymers has been utilized to evidence their miscibility ${ }^{21,34}$. Whereas demixing may be retarded by the slow diffusion of macromolecules, producing apparent homogeneity with immiscible components, spontaneous interdiffusion can only be observed between miscible polymers. To assess the miscibility of the CR and ENR, dynamic mechanical spectra were obtained on a sample consisting of films of the two polymers that had been in contact for varying time periods. It is seen in Figure 2 that distinct glass transitions are observed initially, since the polymers are macroscopically separated. Continued contact, however, alters the dynamic mechanical spectra obtained from the plied film. As the two polymers

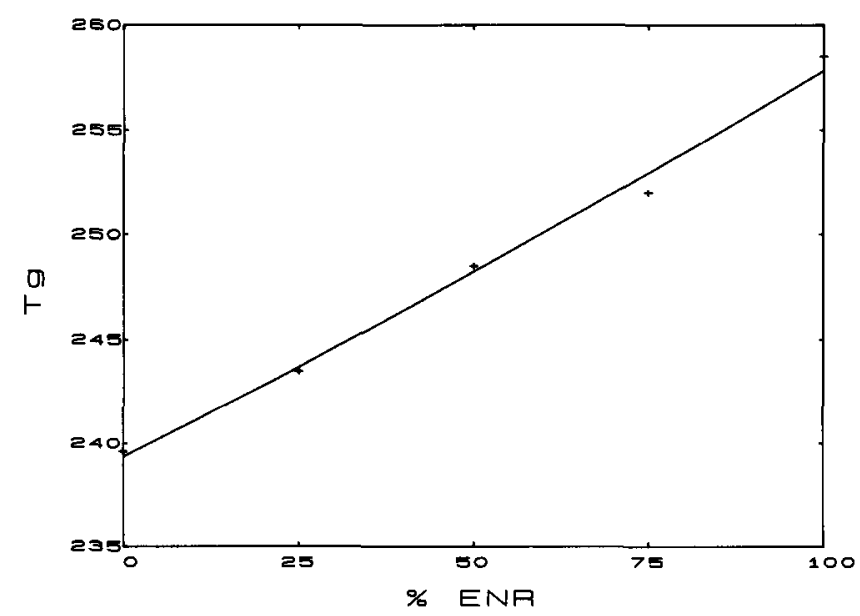

Figure 1 The glass transition temperature obtained from d.s.c. for polychloroprene and epoxidized polyisoprene mixtures. The composition dependence of the glass transition temperature was in accord with equation (3)

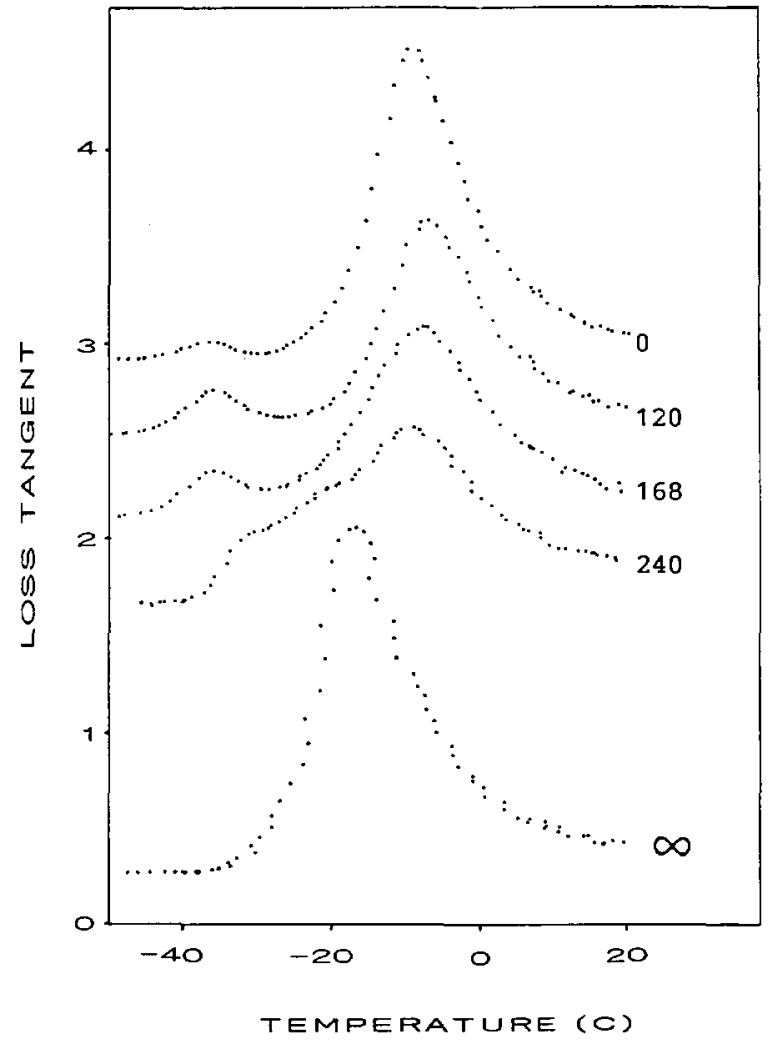

Figure 2 Changes in the mechanical loss tangent of a laminate of CR and ENR, reflecting the interdiffusion at the interface, after the indicated contact times (in hours) at $80^{\circ} \mathrm{C}$. The intensity of the loss tangent maximum associated with the glass transition of the $C R$ is suppressed by the parallel coupling of the two polymers. As spontaneous mixing proceeds, there is an increase in the content of material exhibiting a transition between the glass transition temperatures of the pure components. The data for infinite interdiffusion time were actually obtained by blending the components in solution, then carrying out the dynamic mechanical measurements on the dried film

interdiffuse, the intensity of the measured loss tangent at temperatures intermediate to the $T_{\mathrm{g}}$ of the pure components increases, with a concomitant reduction in the distinct peaks associated with the latter. This spontaneous interdiffusion unequivocally attests to the miscibility of the blend.

It is well known that miscibility in polymer mixtures almost invariably requires specific interaction between the components. Owing to the size of macromolecules, there is only a modest increase in combinatorial entropy upon mixing; hence, even a slightly positive heat of mixing will effect phase separation. The interaction parameter, $\chi$, which provides a measure of the noncombinatorial contributions to the free energy, can be estimated for strictly van der Waals interactions as ${ }^{35}$ :

$$
\chi=(V / R T)\left(\delta_{1}-\delta_{2}\right)^{2}
$$

in which $V$ is a reference volume and $R T$ has its usual significance. The solubility parameter, $\delta$, of ENR is reported to be $8.1\left(\mathrm{cal} \mathrm{cm}^{-3}\right)^{1 / 2}$ (ref. 28). Literature values for CR span a broad range, with an average equal to 8.7 (cal cm$\left.)^{-3}\right)^{1 / 2}$ (ref. 36). Taking $V=100 \mathrm{~cm}^{3}$, from equation (1) $\chi$ is estimated to be $4 \times 10^{-2}$. Miscibility can occur over the entire composition range only with molecular weights for which the critical value of the interaction parameter, given by ${ }^{37}$ :

$$
\chi^{*}=\frac{1}{2}\left(N_{1}^{-1 / 2}+N_{2}^{-1 / 2}\right)^{2}
$$


exceeds $4 \times 10^{-2}$. For the present molecular weights, equation (2) gives $\chi^{*}=5 \times 10^{-4}$. This is significantly less than the $\chi$ arising from the van der Waals contact energies, indicating that the endothermic mixing enthalpy is sufficient to preclude miscibility in the absence of specific interactions. The miscibility observed herein for the ENR and CR mixtures clearly must be a consequence of such interaction.

\section{Specific interaction}

Previously, ENR has been found to be miscible with several chlorinated polymers, with the suggestion made that the oxirane group serves as a proton acceptor. or can be involved in polar interactions ${ }^{25,27}$. Any chemical interaction (e.g. hydrogen bonding, complex formation, charge transfer) occurring between unlike chains in a miscible blend can perturb the vibrational motions of the interacting moieties; thus, infra-red spectroscopy provides a means to identify the existence of specific interactions. A number of reports have described distortions in the infra-red spectra obtained from miscible blends due to specific interactions ${ }^{38-43}$.

FTi.r. spectra were measured for the CR, the ENR and a $50 \%$ by weight blend. A difference spectrum was calculated by subtracting from the blend spectrum the sum of the spectra of the pure components. This difference spectrum would be a weak and featureless background if no specific interactions transpired in the blend, since the blend spectrum would in that case be the linear combination of the pure components' response. In the $2800-3100 \mathrm{~cm}^{-1}$ region a difference spectrum devoid of significant structure was in fact obtained; these frequencies correspond to aliphatic $\mathrm{C}-\mathrm{H}$ vibrational transitions.

Contrasted to this result, bands in the FTi.r. spectrum for the blends known to be associated with vibrations

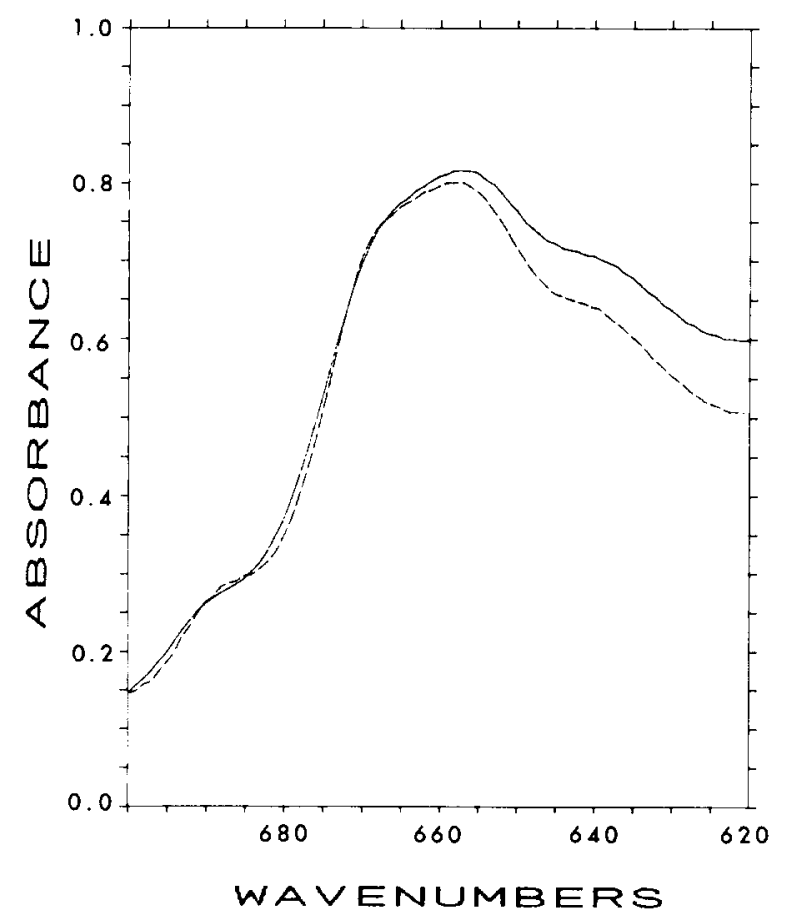

Figure 3 The FTi.r. band associated with the $\mathrm{C}-\mathrm{Cl}$ stretch measured in pure CR (- $)$ and in a 50/50 blend with ENR (--). Differences in the bandshape persisted despite removal of any contribution from the ENR by subtraction of its spectrum using an iterative procedure. This distortion of the band suggests perturbation of the $\mathrm{C}-\mathrm{Cl}$ vibrational motion due to specific interaction with the ENR

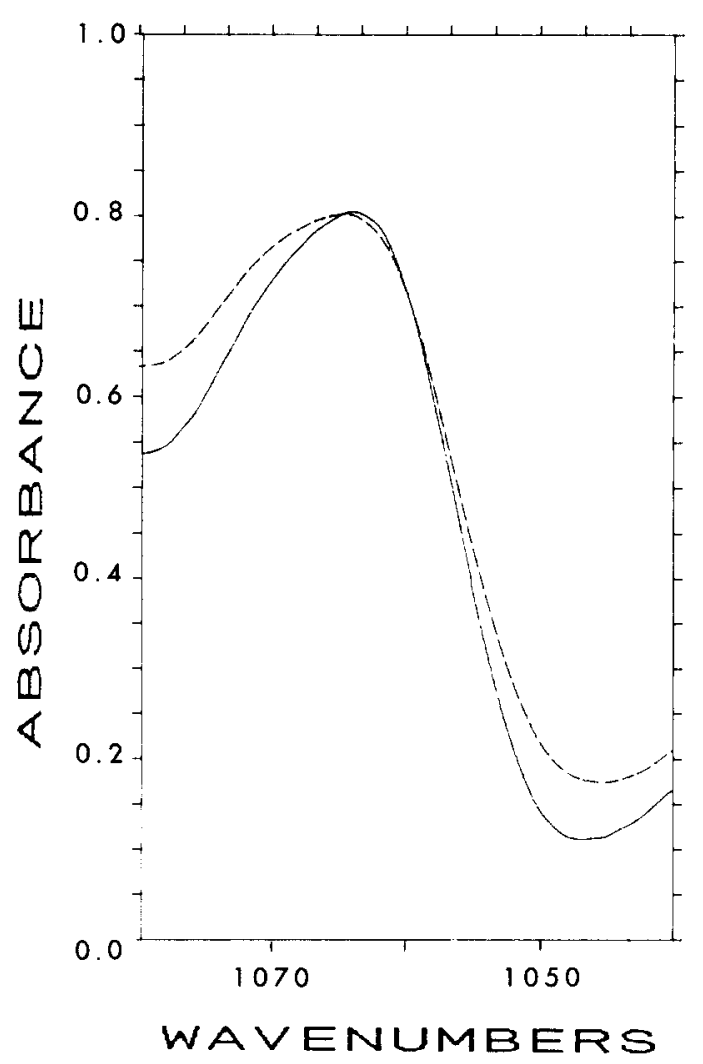

Figure 4 A vibrational band associated with the oxirane group in pure ENR ( - ) and in ENR blended with $50 \%$ CR (-). The distortion of the spectrum occasioned by blending reflects specific interaction involving the oxirane moiety

involving either the chlorine atom in the $\mathrm{CR}^{44}$ or the epoxy moiety of the ENR ${ }^{45}$ were altered in shape and linewidth from the corresponding bands in the pure components' spectra (see Figures 3 and 4). This suggests the existence of specific interaction in the blend involving these groups. An obvious possibility for the interaction is a simple dipolar-dipolar attraction between the electron-rich etheric oxygen of the ENR and the chlorine-containing, polarizable vinyl carbons of the CR. However, it has been shown that the specific interaction of ether moieties with chlorine-substituted aliphatic compounds directly involves the chlorine atom ${ }^{46}$. The exact nature of this interaction remains unclear; however, the $F T 1$.r. spectrum from the blend was only perturbed in the region of vibrational transitions associated with motions involving the chlorine atom (Figures 3 and 4), while the vinylic carbon bands were undistorted (Figure 5 ). Of course the lack of stoichiometry, as well as the configurational constraints imposed by the polymer chain structure, prohibit interaction among all such groups in the blend. Insofar as the measured $F T$ i.r. bands represent the contribution of both interacting and non-interacting species, the extent of the spectral distortions seen in Figures 3 and 4 does not directly parallel the strength of the interaction.

Specific interactions contribute exothermically to the heat of mixing; nevertheless, a net endothermic enthalpy change can result if the van der Waals contact energies, as reflected in the $\chi$ calculated from equation (1), are sufficiently unfavourable. When the interaction parameter for a mixture is positive, phase separation can be induced by increases in molecular weight ${ }^{22,26}$. In an attempt to achieve this, ENR was mixed with higher- 


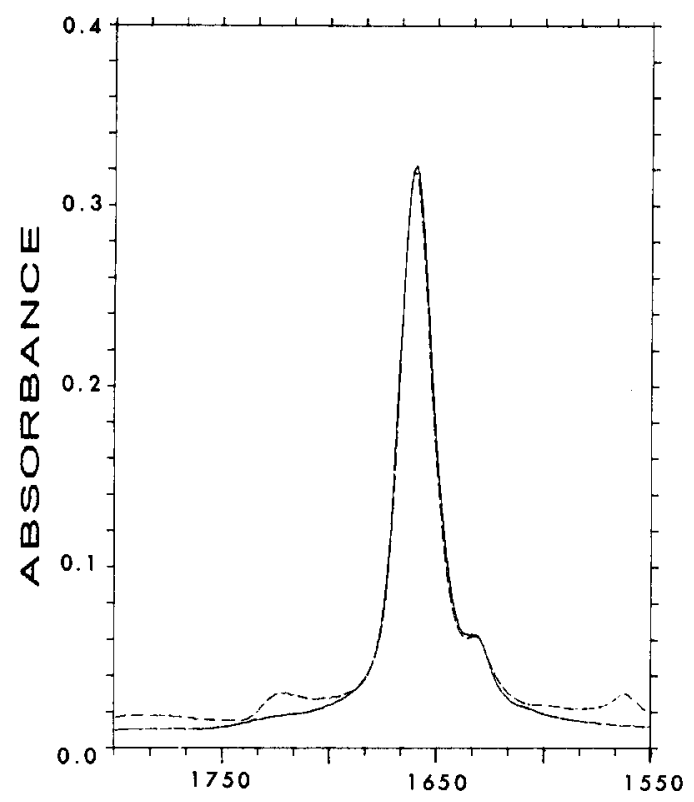

WAVENUMBERS

Figure 5 The $\mathrm{C}=\mathrm{C}$ infra-red band measured in pure $\mathrm{CR}(\longrightarrow)$ and the band from the difference spectrum the $50 / 50$ blend (---). There is no evidence for distortion of the motion of these carbons due to blending, consistent with an interaction that directly involves the chlorine atom. The small band at $1725 \mathrm{~cm}^{-1}$ is from the oxirane group of the ENR. It was not removed through calculation of the difference spectrum

molecular-weight CR (Neoprene WHV). Since specific interactions are responsible for the miscibility, a lower critical solution temperature is expected for the blend $^{12,47,48}$. A $50 \%$ by weight mixture of ENR with the high-molecular-weight CR was annealed for $40 \mathrm{~min}$ at various temperatures up to $120^{\circ} \mathrm{C}$, followed by quenching in the calorimeter to below the glass transition. The ensuing calorimetry scans provided no indication of phase heterogeneity. This inability to induce phase separation by increases in molecular weight is consistent with a negative interaction parameter, although one not necessarily appreciable in absolute magnitude.

The composition dependence of the glass transition temperature of the ENR/CR blends conformed closely to the Fox equation ${ }^{49,50}$ :

$$
1 / T_{\mathbf{g}}=w_{1} / T_{\mathbf{g}, 1}+w_{2} / T_{\mathbf{g}, 2}
$$

where $w$ represents the weight fraction. Previously, negative deviations from this expression have been measured for ENR miscible blends, and interpreted as resulting from strong intermolecular forces ${ }^{25,28}$. The conformity of the data in the present case may reflect the weakness or paucity of the specific interactions in ENR/CR blends.

A direct measure of the interaction parameter for a blend in which one component is crystallizable can be realized from determination of the depression in the equilibrium melting point ${ }^{51}$. The relative stability of the crystalline phase is dependent on the free energy of the amorphous state. Mixing alters this free energy, and thus a connection exists between the melting temperature and the interaction parameter. Specifically, in the approximation of infinite molecular weight:

$$
1 / T_{\mathrm{m}}-1 / T_{\mathrm{m}}^{\circ}=-R / \Delta H_{\mathrm{f}}^{\circ} \chi(1-\phi)^{2}
$$

where $T_{\mathrm{m}}$ and $T_{\mathrm{m}}^{\circ}$ are the respective equilibrium melting points in the blend and in the pure material, $\Delta H_{\mathrm{f}}^{\circ}$ $\left(=8.37 \mathrm{~kJ} \mathrm{~mol}^{-1}\right.$ for polychloropropene $\left.{ }^{52}\right)$ is the perfect crystal excess heat of fusion, and $\phi$ refers to the volume fraction of the crystallizing component. Equilibrium melting points can be determined by extrapolation of experimental melting point data obtained at various temperatures of crystallization to a temperature at which $T_{\mathrm{m}}$ equals the temperature of crystallization ${ }^{53}$. Numerous examples of this approach for the determination of $\chi$ can be found in the literature ${ }^{54-59}$.

This procedure was carried out for the polychloroprene and two blends containing $25 \%$ and $50 \%$ by weight of the ENR. The experimental melting points of the pure $\mathrm{CR}$ and both blends were equivalent at each crystallization temperature within the limit of error. Extrapolation of all the melting point data gives an equilibrium melting temperature for $\mathrm{CR}$ equal to $150^{\circ} \mathrm{C}$ (Figure 6). This is higher than an earlier reported value for a polychloroprene of somewhat different microstructure ${ }^{60}$. Using $T_{\mathrm{m}}^{\circ}=150^{\circ} \mathrm{C}$ and assuming the precision in the measured melting points to be $2^{\circ} \mathrm{C}$, a lower limit for the absolute value of the interaction parameter is found from equation (4) to be $-5 \times 10^{-2}$. The low (albeit negative) magnitude suggests a weakness or low incidence of the interaction between the epoxy group and the vinyl chlorine.

The melting point data were obtained from samples with low levels of crystallinity. It was noted that, notwithstanding the absence of a melting point depression, blending slowed down the rate of crystallization. This is expected for miscible blends, at least at constant $T-T_{\mathrm{g}}$, since crystal growth requires local segregation of the components via diffusion. The alteration of the crystallization rate is expected to be unaccompanied by any suppression of the ultimate degree of crystallinity ${ }^{61}$. Since immiscible blends crystallize without concomitant further segregation, the observation of retarded crystallization can in fact be taken as evidence of a homogeneous morphology.

\section{SUMMARY}

While a substantial number of polymer pairs have been shown to form miscible mixtures, relatively few rubberrubber miscible blends are known. Specific interaction,

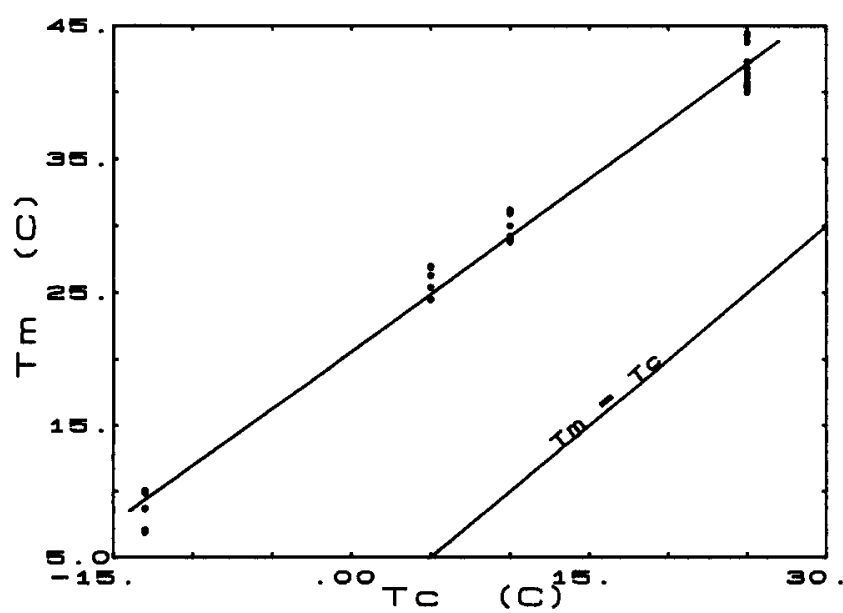

Figure 6 Melting points measured for various crystallization temperatures. There was no significant difference between the data obtained from neat and blended $\mathrm{CR}$, and data from both are included in the figure. The Hoffman-Weeks extrapolation gives $T_{m}^{\circ}=150^{\circ} \mathrm{C}$ 
apparently involving the oxirane moiety on the ENR with the chlorine of the $C R$, confers miscibility to mixtures of polychloroprene and epoxidized natural rubber. The preliminary results described herein concerning the glass transition and crystallization behaviour are consistent with expectations for a miscible blend. Currently the influence of this phase homogeneity on the mechanical and rheological properties is being investigated.

\section{ACKNOWLEDGEMENT}

The support of the Office of Naval Research is gratefully acknowledged.

\section{REFERENCES}

1 Cifra, P., Karasz, F. E. and MacKnight, W. J. Macromolecules $1988,21,446$

2 Curro, J. G. and Schweizer, K. S. J. Chem. Phys. 1988, 88, 7242

3 Roland, C. M. and Trask, C. A. Polym. Bull. 1988, 20, 471

4 Riedl, B. and Prud'homme, R. E. J. Polym. Sci., Polym. Phys. Edn. 1988, 26, 1769

5 Han, C. C., Bauer, B. J., Clark, J. C., Muroga, Y., Matsushita, Y., Okada, M., Tran-cong, Q., Chang, T. and Sanchez, I. C. Polymer 1988, 29, 2002

6 Sanchez, I. C. and Balazs, A. C. Macromolecules 1989, 22, 2325

7 Roland, C. M. J. Polym. Sci., Polym. Phys, Edn. 1988, 26, 839

8 Saito, H., Takahashi, M. and Inoue, T. J. Polym. Sci., Polym. Phys. Edn. 1988, 26, 1761

9 Composto, R. J., Kramer, E. J. and White, D. M. Macromolecules $1988,21,2580$

10 Colby, R. H. Polymer 1989, 30, 1275

11 Kanetakis, J. and Fytas, G. Macromolecules 1989, 22, 3452

12 Flory, P. J. J. Am. Chem. Soc. 1965, 87, 1833

13 Kleiner, L. W., Karasz, F. E. and MacKnight, W. J. Polym. Eng. Sci. 1979, 19, 519

14 Roland, C. M. Rubber Chem. Technol. 1989, 62, 4567

15 Bates, F. S., Dierker, S. B. and Wignall, G. D. Macromolecules 1986, 19, 1938

16 Shah, K., Min, K. and White, J. L. Polym. Eng. Sci. 1988, 28, 1277

17 Takagi, Y., Ougizawa, T. and Inoue, T. Polymer 1987, 28, 103

18 Inoue, T., Shomura, F., Ougizawa, T. and Miyasaka, K. Rubber Chem. Technol. 1985, 58, 873

19 Marsh, P. A., Voet, A., Price, L. D. and Mullens, T. J. Rubber Chem. Technol. 1968, 41, 344

20 Bartenev, G. M. and Kongarov, G. S. Rubber Chem. Technol. $1963,36,668$

21 Roland, C. M. Macromolecules 1987, 20, 2557

22 Trask, C. A. and Roland, C. M. Macromolecules 1989, 22, 256

23 Roland, C. M. and Trask, C. A. Rubber Chem. Technol. 1989 62, 896

24 Fernandes, A. C., Barow, J. W. and Paul, D. R. J. Appl. Polym. Sci. 1986, 32, 6073
25 Margaritis, A. G., Kallitsis, J. K. and Kalfoglou, N..K. Polymer 1987, 28, 2122

Trask, C. A. and Roland, C. M. Polym. Commun. 1988, 29, 332

Margaritis, A. G. and Kalfoglou, N. K. Polymer 1987, 28, 497

Kallitsis, J. K. and Kalfoglou, N. K. Angew. Makromol. Chem. 1987, 148, 103

29 Miller, J. B., McGrath, K. J., Roland, C. M., Trask, C. A. and Garroway, A. N. Macromolecules 1990, 23, 4543

30 Roland, C. M. and Lee, G. F. Rubber Chem. Technol. 1990, 63, 554

31 Ramos, A. R. and Cohen, R. E. Polym. Eng. Sci. 1977, 17, 639

32 Kaplan, D. S. J. Appl. Polym. Sci. 1976, 20, 2615

33 Braun, H. G. and Rehage, G. Angew. Makromol. Chem. 1985, 131, 107

34 Keskkula, H., Paul, D. R., Young, P. and Stein, R. S. J. Appl. Polym. Sci. 1987, 34, 1861

35 'Selected Works of Paul J. Flory' (Eds. L. Mandelkern, J. E. Mark, U. W. Suter and D. Y. Yoon), Vol. I, Stanford Press, 1985 , p. 409

36 'Polymer Handbook' (Eds. J. Brandup and E. H. Immergut), 3rd Edn., Wiley, New York, 1975, p. IV-355

37 de Gennes, P. G. 'Scaling Concepts in Polymer Physics', Cornell University Press, Ithaca, NY, 1979

38 Garcia, D. J. Polym. Sci., Polym. Phys. Edn. 1984, 22, 107

39 Lu, F. J., Benedetti, E. and Hsu, S. L. Macromolecules 1983, 16,1525

40 Varnell, D. F., Runt, J. P. and Coleman, M. M. Macromolecules $1981,14,1350$

41 Coleman, M. M. and Zarian, J. J. Polym. Sci., Polym. Phys. Edn. 1979, 17, 837

42 Fahrenholtz, S. R. and Kwei, T. K. Macromolecules 1981, 14 1076

43 Wellinghoff, S. T., Koenig, J. L. and Baer, E. J. Polym. Sci., Polym. Phys. Edn. 1977, 15, 1913

44 Petcavich, R. J. and Coleman, M. M. J. Macromol. Sci.-Phys. (3) $1980,18,47$

45 Ng, S.-C. and Gan, L.-H. Eur. Polym. J. 1981, 17, 1073

46 Pouchly, J. and Biros, J.J. Polym. Sci., Polym. Lett. 1969, 7, 463

47 Patterson, D. Polym. Eng. Sci. 1982, 22, 64

48 Kammer, H.-W., Inoue, T. and Ougizawa, T. Polymer 1989. 30, 888

49 Couchman, P. R. Macromolecules 1978, 11, 1156

50 Aubin, M. and Prud'homme, R. E. Macromolecules 1988, 21 2945

51 Nishi, T. and Wang, T. T. Macromolecules 1975, 8, 909

52 Maynard, J. T. and Mochel, W. E. J. Polym. Sci. 1954, 13, 235

53 Hoffman, J. D. and Weeks, J. J. J. Res. Natl. Bur. Stand. (A) $1962,66,13$

54 Kwei, T. K., Patterson, G. D. and Wang, T. T. Macromolecules $1976,9,780$

55 Paul, D. R., Barlow, J. W., Bernstein, R. E. and Wahrmund, D. C. Polym. Eng. Sci. 1978, 18, 1225

56 Rim, P. B. and Runt, J. P. Macromolecules 1984, 17, 1520

57 Briber, R. M. and Khoury, F. Polymer 1987, 28, 38

58 Zhang, H. and Prud'homme, R. E. J. Polym. Sci., Polym. Phys. Edn. 1987, 24, 723

59 Margaritis, A. G. and Kalfoglou, N. K. J. Polym. Sci., Polym. Phys. Edn. 1989, 27, 1767

60 Gent, A. N. J. Polym. Sci. (A) 1965, 3, 3787

61 Runt, J. P. and Martynowicz, L. M. Adv. Chem. Ser. 1985, 211 , 111 